\title{
Research on Individualized Training Model of College Students' Engineering Innovation Ability
}

\author{
Yuan Gong1, a, Dan $\mathrm{Mei}^{2}$ \\ ${ }^{1}$ Engineering Training Center, Wuhan University of Science and Technology, Wuhan, Hubei, 430081, \\ China; \\ ${ }^{2}$ College of resource and environmental engineering, Wuhan University of Science and Technology, \\ Wuhan, Hubei, 430081, China; \\ acircless@163.com
}

\begin{abstract}
Innovation is the inexhaustible power of national prosperity and progress. As an important part of training students' practical ability and innovative ability, engineering training is more and more valued by the school. With the national policy guidance and the engineering training internal contradictions, engineering training teaching must reform the training mode, update teaching methods and teaching methods, and enrich the teaching content.We use individual training methods to develop students' autonomy and initiative, stimulate students' original innovation ability, and promote students' engineering innovation ability.
\end{abstract}

Keywords: Individualization, engineering innovative ability, engineering training, practice.

\section{Introduction}

With the development of economy and society, the country is paying more attention to engineering education. The implementation of "Excellence engineers education program", the promotion of engineering education accreditation, putting forward 4.0 in industry and Chinese made 2025 and so on, are required to strengthen the practical ability of students, which require students to have solid professional knowledge, more cannot do without the practice of engineering training. Therefore, the practical teaching of engineering training in Colleges and universities is facing new demands and challenges under the new situation: (1)Policy orientation. The <Outline of the national medium and long term education reform and development program (2010-2020)> clearly pointed out:" Focus on individualized. Pay attention to the students' different characteristics and individual differences, develop the potential of each student"; Meantime, the nation calls 'public entrepreneurship and innovation', actively encourages universities to create conditions, build a platform to support students with innovative ideas to try and cultivate their innovative spirit and innovative consciousness. (2) Internal contradictions are increasingly prominent. With the introduction of a number of advanced manufacturing equipment and technology, such as NC machining, flexible manufacturing system, the contradiction arises between relatively lacking teaching hours and constantly enriching the teaching content. The practice of engineering training from the traditional car clamp milling grinding casting forging welding process, expand to the advanced manufacturing and electrical and electronic technology. Training content is rich, but the relative training hours did not increase, but some also reduced; The contradiction between the complete credit system teaching mode and the centralized training is that the traditional concept of class under the complete credit system is broken, and the students are free to choose courses and attend classes, which makes it impossible for centralized training; Contradiction is generally more students but relatively few machine tools, especially NC machine tools and other advanced manufacturing equipment are short-handed compared to the number of students .

The contradiction between the national policy orientation and the objective existence forced the reform of Engineering Training Practice Teaching. We should cultivate students' innovation ability of engineering oriented, constantly arouse students' enthusiasm and initiative, constructing and implementing the practice of engineering training teaching personalized training mode, teaching individualized, let students interested in more practice opportunities. 


\section{To Strengthen the Ideological Guidance and Set Up The Personalized Practical Education}

Renewal of idea is the premise and foundation of all reform and development. Only from the ideological understanding can be obtained, the essence of reform further minor endings. The engineering training center of teaching administrators, teachers should firmly establish individualized education philosophy, pay attention to the individual differences of students, teaching individualized, cultivated ability, innovation consciousness, innovation spirit and innovation ability of students, to solve complex engineering problems.

In the conceive, design, implement, operation and other links of engineering education, it should be fully advocated the " highlight the personality" as the goal of "open + independent"[1] concept, take the students engineering innovation ability training as the guide, and let the individualization training integrate into the whole process of engineering training practice, playing the autonomy and initiative of students, developing students to solve practical engineering problems. Forming our university personality engineering training practice teaching idea of I-CDIO, and throughout all engineering training the teaching and training, and other aspects of innovation and entrepreneurship, top-down, from teaching management personnel to the guidance of teachers, guidance of teaching practice to realize the harmonization and unification of ideology, practice and education.

\section{To Enrich the Teaching Content of Engineering Training Relying on Academic Advantages}

The enrichment of the teaching content of the engineering training practice is the premise of individual training, the necessary condition of the hierarchical and modular teaching, and the training of engineering innovation ability needs a lot of practice. The transformation of knowledge to quality and ability is largely due to practice and the cross and infiltration of multidisciplinary knowledge. Our school adhere to promote teaching with the discipline construction, pay attention to interdisciplinary training of engineering practice teaching good support and promote, enrich and develop the teaching content of engineering practice, give students more choices and opportunities to practice, provide a guarantee for the individualized training of engineering training. Based on the mechanical manufacturing, automation, electronic information and other advantages of discipline, it is formed by traditional processing technology, advanced manufacturing technology, electrical and electronic technology as the foundation, academic competitions, innovation and entrepreneurship training system for engineering development, then constantly reinforces the foundation of students of engineering training, strengthens the students' ability of basic processing, machine tools and skilled operation, increases the overall design, practice and innovation opportunities, focuses on cultivating students' practical ability and innovation ability of engineering.

\section{To Teach Individualized And Implement Engineering Training Teaching In Personalized Training Mode}

\subsection{To build and implement the "three-level, three-capacity, multi-module" personalized training mode}

Personalized education is the cultivation of innovative talents and the quality of education, to develop students' character. Its essence is to respect the inherent potential of students, respect for students' personal interests and self-development desire. At the same time because of its wide audience, individual differences and interests of the different needs of the implementation of different levels of training $^{[2]}$. In 2012, engineering training began to implement the "module + level" [3] teaching system reform. With years of practice and improvement, and it ultimately established a "three-level, three-capacity, multi-module" personalized training model for engineering training practice teaching. This model aims at individualized training, and constantly optimizes the teaching content of engineering training practice, stimulates students' enthusiasm for learning independently, forms a long - term mechanism and effective method of cultivating engineering innovation ability. 
According to the different professional ,there is a need to reform engineering training practice teaching personnel training program, and set up engineering training practice teaching "three levels", namely engineering cognition and basic training, basic skills training and multidisciplinary knowledge integration practice, comprehensive innovation practice training; Corresponding to the "three capabilities", that is, the basic practical ability, professional practice ability, and practical innovation ability; According to the "three-level, three-capacity" division, the engineering training practice teaching each type is divided into 2-4 relatively independent and progressive operation module, namely "multi-module". Students according to their professional requirements, complete the corresponding operation of the module of training, then they can get the corresponding credit and ability level, if interested, students can continue to choose the training module to the next level, just like the game. In the case of resources permit, students can freely choose the training module and training time. What to learn, what to learn are by their own words, which greatly stimulated the enthusiasm of students' autonomous learning, and students in the comprehensive innovation training, can participate in the competition, creativity, innovation and entrepreneurship that greatly enhance the students' practice engineering practical ability and innovation ability.

\subsection{To build an open practice teaching platform}

The construction of practical teaching platform is the foundation of protecting individual training. Our school continues to improve the practice of engineering training teaching platform of software and hardware construction, build engineering training teaching service platform, virtual simulation teaching platform and mobile micro-platform and other three platforms combined open practice teaching platform, which fully meet the individual needs of students training. Among them, the engineering training teaching service platform is to meet the basic teaching needs, to achieve students online selection training module, query schedule and notice, training appointment and other functions, which provides convenience for students to arrange their own learning process, learning content and learning time; At the same time, the school use of information technology means to create a virtual simulation training platform. Students can achieve virtual simulation through the computer operation, breaking the training time, place restrictions, for achieving all-weather operation practice. Students can carry out a variety of machine tool operation training at anytime and anywhere, which provide a useful complement to the practice of the field, to achieve "class + class", "virtual + reality" of the organic combination; With mobile micro-platform to achieve the sharing of high-quality resources, students can browse teaching micro-video at anytime, anywhere. Learning from the intuitive sensibility to the practice will be better to enhance the effectiveness of teaching practice. At the same time, mobile micro - platform realizes instant communication and answering, which is better to meet the students' doubts of knowledge.

\subsection{To increase the intensity of science and technology competition}

Science and technology competition is an important starting point for engineering training practice teaching, is to further promote the quality of teaching practice, and to enhance the practical ability of students to protect the ability. Reading for understanding, then using. Our school has always attached importance to student science and technology competition activities, and gradually improves the engineering training school competition, outside the participating system, the implementation of the school, provincial, national competition mechanism, 'competition with training, to practice and promote competition', carries out design, operation, processing, runs a full range of engineering training competitions, so that students can learn with the purpose to practice. Increasing the competition intensity, yearly the school carries out engineering training of college student basic skills competition, aeromodelling competition, Hui fish design competition, adding competition project, and expands its coverage and encourage more students interested in participating in competitions. Then students can enhance their ability in practice training and competition innovation. Also the school actively encourages and supports students to participate in the provincial, national events, to give students more practice of actual combat opportunities, and to build a student competition award winning exhibition exchange platform, to carry out regular exchange activities for students to exchange Innovation, display results, share resource. 


\subsection{To stimulate college students creative innovation and entrepreneurship}

The school actively explores effective measures to encourage students' creativity, innovation and entrepreneurship, promotes and supports the students to carry out innovative design, innovative manufacturing, sets engineering training innovation credits, and incorporates it into the practice of engineering training in total credits, and encourages students to use their thinking, design works, then do themselves to make it a reality. Building a passenger space among the school, the Communist Youth League, academic institutions and related institutions relying on existing resources, equipment and teaching advantages makes it good to provide innovative and entrepreneurial platform for the students to create a good atmosphere of innovation and entrepreneurship. Teachers should actively guide and encourage students to participate in innovation and entrepreneurship, guide students to innovation and entrepreneurship projects, using the existing CNC machining, 3D printing, laser engraving and other advanced manufacturing equipment, and should also provide strong technical support for students, innovation and entrepreneurship ,encourage all school students, to try to innovate and take the first step.

\section{To Strengthen the Process of Supervision, Improve the Scientific Evaluation System}

Scientific evaluation mechanism contributes to motivating students' enthusiasm of independent study and the improvement of practical and innovative ability. Establishing and strengthening scientific evaluation and evaluation index system must strengthen process supervision. The study practice and innovation situations in students' practical training should be fed back in time. Except for Basic theory examination results and each module of the practice operation results, the results in online studying, course contests, creativity, innovation, entrepreneurship and other aspects will be involved in evaluation index system. Further motivating students' enthusiasm of learning and satisfying students' need of personalized training adequately can provide advantages for cultivating engineering and innovation abilities. Scientific evaluation mechanism contributes to motivating students' enthusiasm of independent study and the improvement of practical and innovative ability. Establishing and strengthening scientific evaluation and evaluation index system must strengthen process supervision. The study practice and innovation situations in students' practical training should be fed back in time. Except for Basic theory examination results and each module of the practice operation results, the results in online studying, course contests, creativity, innovation, entrepreneurship and other aspects will be involved in evaluation index system. Further motivating students' enthusiasm of learning and satisfying students' need of personalized training adequately can provide advantages for cultivating engineering and innovation abilities.

\section{Summary}

The engineering training practice teaching is the comprehensive practice teaching segment of the balance of theoretical teaching and practical operation. It is also the important carrier of developing students' practical ability, creative spirit and creative ability. We must make a breakthrough in deepening reform of the innovation entrepreneurship education, inspire students' innovative consciousness and mobilize students' innovation practice enthusiasm in a large degree to cultivate a batch of high-quality and creative talents who can solve complex engineering problems for the country's construction.

\section{References}

[1] Cheng Guangwen, Gong Yuan. Research on the reform of talent training mode in local colleges and Universities[J]. China University Teaching, 2015(11):33.

[2] Fu Li-ling, Yang Ping etc. Exploring the New Mode of Engineering Training to Implement Personalized Hierarchical Cultivation[J]. Research and exploration in laboratory, 2013,32(1):86. 
[3] Gong Yuan, Mei Dan. Study on the system reform of metalworking practice teaching in engineering colleges and Universities[J].China Electric Power Education, 2013(2):130. 